\title{
Outcome Study of the Pipeline Embolization Device with Shield Technology in Unruptured Aneurysms (PEDSU)
}

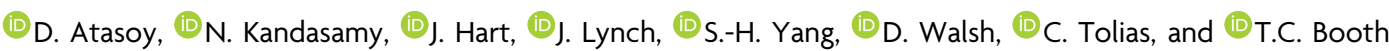

\begin{abstract}
BACKGROUND AND PURPOSE: The recently introduced Pipeline Flex Embolization Device with Shield Technology (Pipeline Shield) is the third generation of Pipeline flow-diverter devices. It has a new stent-surface modification, which reduces thrombogenicity. We aimed to evaluate clinical and radiographic (safety and efficacy) outcomes of the Pipeline Shield.
\end{abstract}

MATERIALS AND METHODS: The 30-day and 1-year mortality and morbidity rates and the 6- and 18-month radiographic aneurysm occlusion outcomes for procedures performed between March 2016 and January 2018 were analyzed. 3D-TOF-MRA was used for follow-up.

RESULTS: Forty-four attempted Pipeline Shield procedures were performed for 41 patients with 44 target aneurysms (total of 52 aneurysms treated). A total of $88.5 \%$ of devices were inserted in the anterior circulation, and $11.5 \%$, in the posterior circulation; 49/52 (94.2\%) aneurysms were saccular; and 1/52 (1.9\%) was fusiform. One (1.9\%) aneurysm was an iatrogenic pseudoaneurysm, and 1 (1.9\%) was a dissecting aneurysm. Seventy-one percent (35/49) of the saccular aneurysms were wide-neck (neck, $>4 \mathrm{~mm}$ ), 34.6\% $(18 / 52)$ were large $(\geq 10 \mathrm{~mm})$, and $3.8 \%(2 / 52)$ were giant $(\geq 25 \mathrm{~mm})$. The mean aneurysm sac maximal diameter was $9.0 \mathrm{~mm}$, and the mean neck width was $5.0 \mathrm{~mm}$. The cumulative mortality and morbidity rates were $2.3 \%$ and $6.8 \%$ at 1 year, respectively. The adequate occlusion rate was $78.8 \%$ at 6 months and $90.3 \%$ at 18 months.

CONCLUSIONS: In this pragmatic and non-industry-sponsored study, the occlusion rates and safety outcomes were similar to those seen in previously published studies with flow-diverter devices and earlier generation Pipeline Embolization Devices.

$\mathbf{F}$ ow-diverter devices have been used to treat cerebral aneurysms for nearly 10 years. These devices occlude aneurysms through endoluminal reconstruction and remodeling of the parent artery. ${ }^{1}$ The Pipeline Embolization Device (PED; Covidien, Irvine, California) is 1 of $2 \mathrm{FDA}$-approved flow-diverter devices. ${ }^{2}$ The first generation of PEDs has been used effectively and safely for many years. ${ }^{3-5}$ The second generation, the Pipeline Flex

Received June 1, 2019; accepted after revision September 20

From Karadeniz Technical University (D.A.), Farabi Hospital, Trabzon, Turkey; Departments of Neuroradiology (N.K., J.H., J.L., T.C.B.) and Neurosurgery (D.W., C.T.), King's College Hospital National Health Service Foundation Trust, London, UK; Department of Radiology (S.-H.Y.), Wan Fang Hospital, Taipei Medical University, Taipei, Taiwan; Department of Radiology (S.-H.Y.), School of Medicine, College of Medicine, Taipei Medical University, Taipei, Taiwan; and School of Biomedical Engineering and Imaging Sciences (T.C.B.), King's College London, London, UK.

This work was supported by the Wellcome/Engineering and Physical Sciences Research Council Center for Medical Engineering (WT 203148/Z/16/Z).

Paper previously presented at: Annual Meeting of the American Society of Neuroradiology, May 18-23, 2019; Boston, Massachusetts.

Please address correspondence to Thomas C. Booth, EDiNR, DMCC, MA, MBBS, MRCP, FRCR, PhD, Department of Neuroradiology, King's College Hospital NHS Foundation Trust, London SE5 9RS, UK; e-mail: tombooth@doctors.org.uk; @ThomasCBooth

--- Indicates open access to non-subscribers at www.ajnr.org

http://dx.doi.org/10.3174/ajnr.A6314
Embolization Device (Covidien), had a redesigned delivery system enabling better repositioning and redeployment of the stent. ${ }^{6,7}$ Nonetheless, thromboembolic complications remain an important cause of morbidity in both generations of PEDs. ${ }^{3}$ Thus, a third generation, the Pipeline Flex Embolization Device with Shield Technology (Pipeline Shield; Covidien) was recently produced (Fig 1). The second-generation delivery system remained the same; however, there is a new phosphorylcholine stent-surface modification aimed at minimizing thrombogenicity. ${ }^{8}$ Because there is no difference in cost between the Pipeline Shield and earlier PED devices, the Pipeline Shield has been adopted as the default PED, though there are limited clinical data to support its use. In this study, we demonstrate clinical and radiographic (safety and efficacy) outcomes of the third-generation PED.

\section{MATERIALS AND METHODS Patient Selection}

All patients who underwent Pipeline Shield placement at a single center between March 2016 and January 2018 were included in this pragmatic and retrospective cohort study. All cases were selected following a consensus decision at a neurovascular 


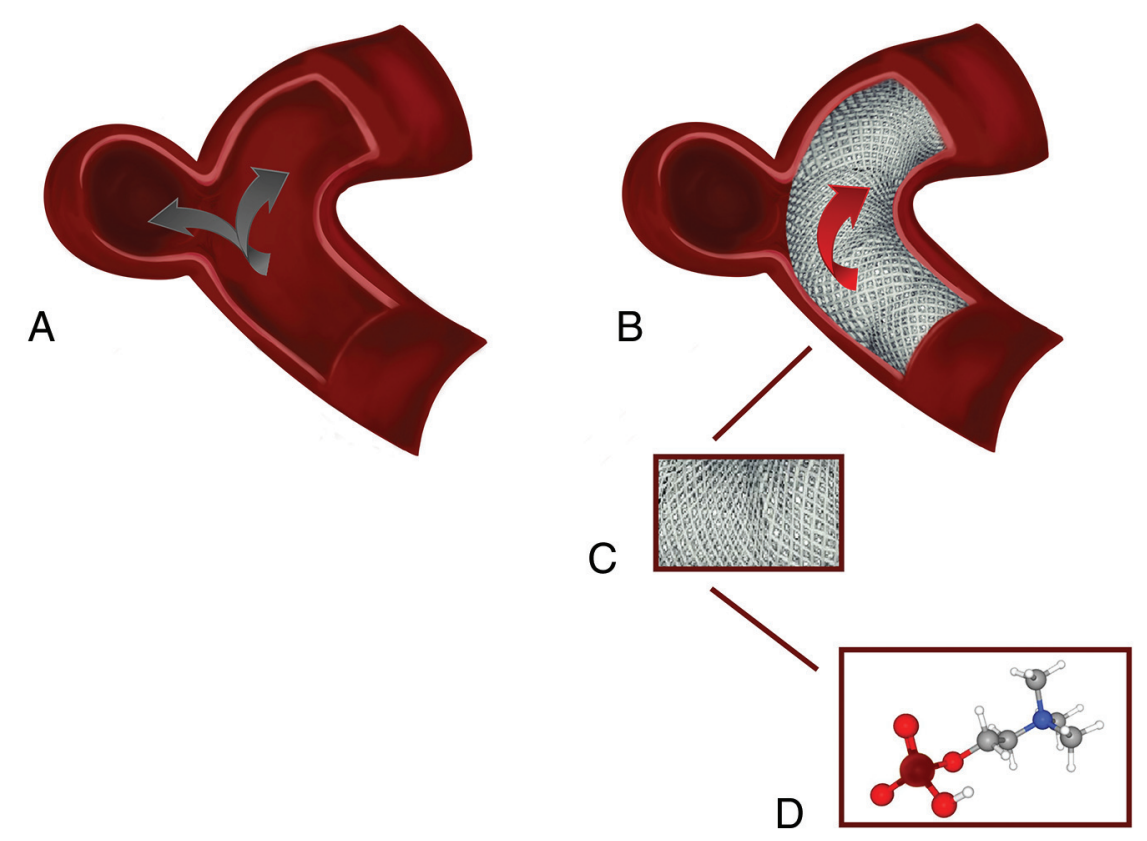

FIG 1. Illustration of Pipeline Shield mechanism and structure. A, Before Pipeline Shield deployment, the blood flow is through both the parent artery and the aneurysm. $B$, However, after device deployment, the blood flow in the aneurysm is reduced or disrupted. C, A schematic showing the magnified appearance of the braided wires of the Pipeline Shield. D, A 3D illustration of the phosphorylcholine molecule, which is covalently bound onto the bare metal wires in a polymer form, resulting in physiologic imitation of the cell membrane.

multidisciplinary team meeting, which included interventional neuroradiologists and neurovascular surgeons. A high neck-tosac ratio, a high probability of aneurysm recurrence, and increased neurosurgical technical difficulty were the factors leading to Pipeline Shield treatment in preference to coiling, stentassisted coiling, or neurosurgery. ${ }^{9}$

\section{Procedural Details}

Patients started dual-antiplatelet therapy (aspirin and clopidogrel) 7 days before their procedure and continued clopidogrel once daily for 6-9 months and continued aspirin for life (all doses, $75 \mathrm{mg}$ daily). Platelet-resistance testing was not performed at our center due to our interpretation of the literature indicating a lack of evidence to show a proven clinical benefit. ${ }^{10-13}$

Pipeline Shield placement procedures were performed with the patient under general anesthesia using biplane angiography (Allura Xper FD, Philips Healthcare, Amsterdam, Netherlands). All procedures were performed with a femoral arterial approach with $6 \mathrm{~F}$ or $8 \mathrm{~F}$ guiding-catheter systems (0.088-inch NeuronMax or 6F Benchmark, both Penumbra, Alameda, California; Shuttle guide sheath, Cook, Bloomington, Indiana), which were positioned in the cervical segment of the ICA ipsilateral to the target aneurysm or a distal V2 segment. A triaxial system, incorporating a 0.058 - or 0.072-inch intracranial support catheter (Navien, Covidien, Irvine, California) was used in both the anterior and posterior circulations. The Pipeline Shield device was deployed using a 0.027 -inch microcatheter (Phenom 27 or Marksman; both Covidien). Embolization catheters (Echelon, Covidien; or Excelsior SL10, Stryker, Kalamazoo, Michigan) were used for adjunctive coil delivery in selected cases. Patients typically were discharged home the morning after the procedure.

\section{Data Collection}

Electronic patient records (Allscripts Sunrise, Chicago, Illinois); preprocedural, procedural, and postprocedural images on the PACS; and written procedural records for patients treated with the Pipeline Shield were reviewed. Data on aneurysm size and location were acquired from DSA images (Allura Xper FD, Philips Healthcare, Amsterdam, Netherlands). As in a previous PED study, ${ }^{9}$ the first posttreatment follow-up was performed typically at 6 months postprocedure using 3D-TOF-MRA (Signa $1.5 \mathrm{~T}$ HDX; GE Healthcare; or AERA 1.5T, Siemens, Erlangen, Germany) with respective $\mathrm{TR}=23$ or $25 \mathrm{~ms}, \mathrm{TE}=2.5$ or $7 \mathrm{~ms}$, flip angle $=20^{\circ}$ or $25^{\circ}$ (with ramped pulse), matrix $=320 \times 224$ or $241 \times 256$; FOV $=19 \times 19$ or $18 \times$ $18 \mathrm{~cm}$, section thickness $=1.4 \mathrm{~mm}$ (reconstructed to 0.7 or $0.5 \mathrm{~mm}$, respectively). If there were new clinical features during follow-up, an earlier MR imaging (with MRA) or CT (with CTA) was performed on a case-by-case basis. All images were reviewed in the neurovascular multidisciplinary team meeting, and further follow-up 3D-TOF-MRA was typically scheduled for 18 months postprocedure. All data were reviewed and analyzed by an independent core laboratory (D.A.).

Aneurysm occlusion status was classified using the RaymondRoy Outcome Classification (Raymond Scale): class 1, complete occlusion; class 2, residual neck; and class 3, residual aneurysm. To compare our results with those of the largest clinical trial of PEDs to date (the International Retrospective Study of the Pipeline Embolization Device (InttrePED) ${ }^{3}$ ), we used the identical adverse event classification. A neurologic adverse event included rupture of the target aneurysm causing subarachnoid hemorrhage or carotid cavernous fistula, intraparenchymal hemorrhage, ischemic stroke, parent artery stenosis, and cranial neuropathy. A persistent clinical deficit at 7 days following the event was defined as a "major" adverse event. Other events that resolved within 7 days with no clinical sequelae were defined as "minor" adverse events.

\section{Statistical Analysis}

Descriptive and comparative statistical analyses were performed using SPSS (Version 23.0; IBM, Armonk, New York). Student $t$ tests or Mann-Whitney tests were used. All adverse events were reviewed on an intention-to-treat basis. Aneurysm characteristics and occlusion rates were performed on a peraneurysm basis because some patients had $>1$ aneurysm treated with $\geq 1$ PED. 


\begin{tabular}{|cc|}
\hline \multicolumn{1}{c}{ Characteristic } & $\begin{array}{c}\text { No. (\%) or } \\
\text { Mean (Range) }\end{array}$ \\
\hline Aneurysm location & \\
Anterior circulation $^{\text {a }}$ & $46(88.5)$ \\
ICA cavernous segment & $2(3.8)$ \\
ICA paraophthalmic segment & $29(55.7)$ \\
ICA posterior communicating segment & $12(23.1)$ \\
ICA terminal segment & $2(3.8)$ \\
M1 segment of MCA & $1(1.9)$ \\
Posterior circulation & $6(11.5)$ \\
Basilar artery & $3(5.8)$ \\
Vertebral artery & $2(3.8)$ \\
Posterior cerebral artery & $1(1.9)$ \\
Neck width (mm ${ }^{b}$ ) & $5.0(1.0-21.0)$ \\
Maximum aneurysm sac diameter (mm ${ }^{b}$ ) & $9.0(1.0-28.0)$ \\
$<10$ & $32(60.8)$ \\
10-25 & $18(34.6)$ \\
$\geq 25$ & $2(3.8)$ \\
PED number (per aneurysm) & $0.86(45 / 52)$ \\
Adjunctive coils placed & $15(28.8)$ \\
\hline${ }^{a}$ ICA according to the New York University classification. ${ }^{14}$ & \\
${ }^{b}$ Millimeter to the nearest 0.5.
\end{tabular}

\section{Ethical Statement}

Written informed consent was obtained from all patients. We received written confirmation from the Research and Innovation Department at King's College Hospital that the Health Research Authority of the UK does not require review by a Research Ethics Committee, given the nature of the retrospective study using deidentified data. The study was performed in accordance with the ethical standards laid down in the 1964 Declaration of Helsinki and its later amendments.

\section{RESULTS}

\section{Patient and Aneurysm Characteristics}

There were 41 patients between March 2016 and January 2018 whom we intended to treat with the Pipeline Shield device. The mean age was 56 years (range, $17-82$ years), and $68.3 \%$ (28/41) of patients were women.

There were no acutely ruptured aneurysms. There had been prior treatment of intracranial aneurysm with coils in 32.6\% (17/ 52) of aneurysms. The mean aneurysm neck width was $5.0 \mathrm{~mm}$, the mean sac maximal diameter was $9.0 \mathrm{~mm}, 34.6 \%$ (18/52) were large $(\geq 10 \mathrm{~mm})$, and $3.8 \%(2 / 52)$ were giant $(\geq 25 \mathrm{~mm})$ (Table 1). Forty-nine (94.2\%) aneurysms were saccular, and 1 (1.9\%) was fusiform. One (1.9\%) aneurysm was an iatrogenic pseudoaneurysm, and 1 (1.9\%), a dissecting aneurysm. Seventy-one percent (35/49) of the saccular aneurysms were wide-neck (neck, $>4 \mathrm{~mm}$ ). Most aneurysms were located in the anterior circulation, $46 / 52$ (88.5\%); 6/52 (11.5\%) were located in the posterior circulation.

A total of 44 attempted Pipeline Shield procedures were performed for the 41 patients with 44 target aneurysms (total, 52 aneurysms treated; there were 8 cases in which the device covered additional nontarget aneurysms). Three patients who had been treated for ICA aneurysms had a second Pipeline Shield procedure for aneurysms located in the contralateral ICA within 1 month. Two patients each received 2 Pipeline Shields for 1 target aneurysm in a single procedure. Device-deployment success
Table 2: Clinical outcomes

\begin{tabular}{|c|c|}
\hline Outcome & $\begin{array}{c}\text { Procedure } \\
\text { No. (\%) }\end{array}$ \\
\hline \multicolumn{2}{|l|}{ Periprocedural outcomes (within 30 days) } \\
\hline \multicolumn{2}{|l|}{ Major adverse events ${ }^{a}$} \\
\hline Death from subdural hemorrhage & $1(2.3)$ \\
\hline Cranial nerve palsy ${ }^{\mathrm{b}}$ & $1(2.3)$ \\
\hline \multicolumn{2}{|l|}{ Minor adverse events } \\
\hline Stroke/TIA & $1(2.3)$ \\
\hline Headache $^{\text {b }}$ & $1(2.3)$ \\
\hline \multicolumn{2}{|l|}{ Postprocedure outcomes ( 30 days to $1 \mathrm{yr}$ ) } \\
\hline \multicolumn{2}{|l|}{ Major adverse events ${ }^{a}$} \\
\hline Pulsatile tinnitus (carotid cavernous fistula) & $1(2.3)$ \\
\hline Mass effect causing reduced visual acuity & $1(2.3)$ \\
\hline
\end{tabular}

(release of the Pipeline Shield at the target site) was achieved in 45 of 46 (97\%) of the attempted Pipeline Shield deployments. It was not possible to deploy a Pipeline Shield in 1 patient who had a wide-neck saccular M1 segment aneurysm. Deployment was unsuccessful because the Pipeline Shield would not travel through the Marksman catheter, which was within a 0.058 Navien intracranial support catheter placed inside a tortuous cervical ICA. The aneurysm was subsequently treated with a LEO Baby stent (Balt Extrusion, Montmorency, France) and coils. Stable complete occlusion (Raymond scale 1) at 18-month follow-up was seen. In total, 45 devices were deployed in the 44 procedures. The mean number of deployed devices per aneurysm was $0.86(45 / 52)$ or, if nontarget aneurysms were ignored, 1.02 (44/45). No thromboembolic or hemorrhagic events occurred during the procedures.

\section{Periprocedural Clinical Outcomes}

The periprocedural mortality rate was $1 / 44$ (2.3\%) Pipeline Shield procedures (Table 2). This patient had a recurrent giant basilar termination aneurysm after previous coiling treatment. This aneurysm measured $27 \mathrm{~mm}$ in maximum dimension with a $10-\mathrm{mm}$ recurrent sac diameter. He had an acute subdural hematoma 15 days after the successful Pipeline Shield deployment with adjunctive coiling and died 16 days after the procedure. There were 2 periprocedural major events including this death, 2/44 (4.6\%). The second major event gave a periprocedural neurologic morbidity rate of $2.3 \%$ (1/44). This patient was treated with 2 Pipeline Shield devices for a giant $(28 \mathrm{~mm})$ right cavernous segment ICA aneurysm. On day 7 postprocedure, the patient was re-admitted with an ipsilateral third nerve palsy. A head CT revealed the expected appearances of a thrombosed aneurysm. The third cranial nerve palsy was attributed to the thrombosed aneurysm. At the time of presentation, the patient also experienced a headache (Universal Pain Assessment Tool for headache, 5/10). CT of the head also showed a new small remote right temporal intraparenchymal hematoma. The patient was managed symptomatically for headache, and in view of the hemorrhage, clopidogrel was stopped temporarily with the patient continuing on aspirin. Following appropriate evolution of the right temporal hemorrhage on follow-up CT, clopidogrel therapy was restarted and the patient was discharged with no headache. There were 2 periprocedural minor events, including the headache described here, 


\begin{tabular}{lc}
\hline \multicolumn{1}{c}{ Outcome } & $\begin{array}{c}\text { Aneurysm } \\
\text { No. (\%) or } \\
\text { Mean (Range) }\end{array}$ \\
\hline Adequate occlusion/remodeling at 6 months (Raymond scale 1 and 2) & $41(78.8)$ \\
$\quad$ No residual neck or sac (Raymond scale 1) & $36(69.2)$ \\
$\quad$ Residual neck (Raymond scale 2) & $5(9.6)$ \\
Residual sac (Raymond scale 3) & $11(21.1)$ \\
Adequate occlusion/remodeling at 18 months (Raymond scale 1 and 2) & $47(90.3)$ \\
$\quad$ No residual neck or sac (Raymond scale 1) & $43(82.7)$ \\
Residual neck (Raymond scale 2) & $4(7.7)$ \\
$\quad$ Residual sac (Raymond scale 3) & $5(9.6)$ \\
Mean size of aneurysms (mm) & \\
Residual sac (Raymond scale 3) & $11.5(4.0-22.0)$ \\
No residual neck or sac (Raymond scale 1) & $8.5(1.0-28.0)$ \\
Mean size of neck (mm) & \\
$\quad$ Residual sac (Raymond scale 3) & $8.0(3.0-21.0)$ \\
$\quad$ No residual neck or sac (Raymond scale 1) & $4.5(1.0-16.0)$ \\
\hline${ }^{a}$ Millimeter to the nearest 0.5. &
\end{tabular}

${ }^{a}$ Millimeter to the nearest 0.5 .

with a total of $2 / 44(4.6 \%)$. The second minor event yielded a $2.3 \%$ (1/44) stroke/TIA rate. This patient had a TIA with a temporary left-sided facial droop and slurred speech 6 days after right ICA PED deployment. CT, MR imaging, and MRA showed no intracranial hemorrhage or recent infarct. The patient was also known to have atrial fibrillation and was referred to the TIA clinic.

\section{MRA Outcomes}

Follow-up MRA was performed in 38/40 patients who had undergone technically successful procedures. One patient died 16 days postprocedure, and the other patient refused imaging follow-up (the patient is clinically healthy). The mean follow-up time until the first MRA was 5.8 months (range, 1-7 months).

Within 6 Months. We classified 3 aneurysms as nonoccluded1 because the first follow-up MRA was performed after 6 months (despite the follow-up >6-month MRA showing occlusion). Similarly, we classified the aneurysm in the patient who refused follow-up imaging as nonoccluded. Therefore, within 6 months, $78.8 \%$ (41/52) of aneurysms achieved adequate occlusion (Raymond scale 1 or 2 ) or remodeling (1 dysplastic fusiform and 1 dissecting aneurysm) (Table 3 ). The complete occlusion rate (Raymond scale 1 ) was $69.2 \%(36 / 52)$. A residual aneurysm sac remnant (Raymond scale 3 ) was seen in $21.1 \%(11 / 52)$ of aneurysms at 6 months.

Between 6 and 18 Months. We classified the aneurysm in the patient who refused follow-up imaging as nonoccluded. The mean follow-up time until the second MRA was 17.2 months (range, 7-20 months). Six additional aneurysms were completely occluded (Raymond scale 1). The total adequate occlusion rate (Raymond scale 1 and 2) in this study was 90.3\% (47/52), and the complete occlusion rate (Raymond scale 1) was $82.7 \%(43 / 52)$ at 18 months.

The maximum sac diameters of aneurysms with residual sac filling (Raymond scale 3) and aneurysms that showed complete occlusion (Raymond scale 1 ) were not significantly different $(P=$ .28; mean, $11.5 \mathrm{~mm}$ [range, $4.0-22.0 \mathrm{~mm}$ ] versus mean, $8.5 \mathrm{~mm}$ [range, $1.0-28.0 \mathrm{~mm})$ ]. The neck width of aneurysms with residual sac filling (Raymond scale 3) was not significantly different from that of those with complete occlusion (Raymond scale 1) ( $P=.10$; mean, $8.0 \mathrm{~mm}$ [range, $3.0-21.0 \mathrm{~mm}$ ] versus mean, $4.5 \mathrm{~mm}$ [range, 1.0-16.0 mm]).

No in-stent stenosis was identified at either follow-up time point.

In summary, the adequate occlusion rate and the complete occlusion rate were $78.8 \%(41 / 52)$ and $69.2 \%$ (36/52), respectively, at 6 months. At 18 months, the adequate occlusion rate was $90.3 \%(47 / 52)$ and the complete occlusion rate was $82.7 \%$ (43/ 52).

\section{Postprocedural Clinical Outcomes 30 Days to 1 Year}

One patient experienced blurry vision 3 months following the procedure, and ophthalmologic examination showed papilledema (Table 2). MRA at 5 months postprocedure showed that there was residual neck filling (Raymond Scale 2; 8 -mm neck remnant) in a paraophthalmic segment aneurysm (Fig 2). The stent was no longer covering the entire aneurysm neck, and the aneurysm cross-sectional diameter had increased during the 5-month interval from 17 to $32 \mathrm{~mm}$. The aneurysm was re-treated with a larger diameter flow-diverter device, the Flow-Redirection Endoluminal Device (FRED; MicroVention, Tustin, California), which was deployed across the uncovered neck. The rationale was that this larger stent would give superior apposition to the parent vessel lumen distal to this segment. MRA performed 1, 2, and 6 months after the second procedure showed stability of the aneurysm cross-sectional diameter with a reduction in the neck remnant size (Raymond Scale 2; $4 \mathrm{~mm}$ ).

There was 1 further major adverse event. This patient had a recurrent left cavernous segment ICA 9.5-mm wide-neck aneurysm after coiling. During the procedure, there was a transient iatrogenic carotid cavernous fistula, which had resolved by the end of the procedure when the Pipeline Shield was satisfactorily deployed across the neck of the aneurysm. However, the patient presented with sudden-onset pulsatile tinnitus 1 month later, and DSA showed that there was recurrent carotid cavernous fistulation (note that because our methodology used the IntrePED study adverse event classification as described above, this was classified as a postprocedural event). This fistula was treated with coil embolization. There were no further clinical sequelae.

Cumulative adverse events of any sort occurred after treatment of 4 anterior circulation aneurysms from a total of 38 (10.5\%) target aneurysms. There was 1 adverse event (periprocedural subdural hematoma) that occurred after treatment of a posterior circulation aneurysm from a total of $6(16.7 \%)$ target aneurysms.

No aneurysms ruptured periprocedurally or at 1-year follow-up. 

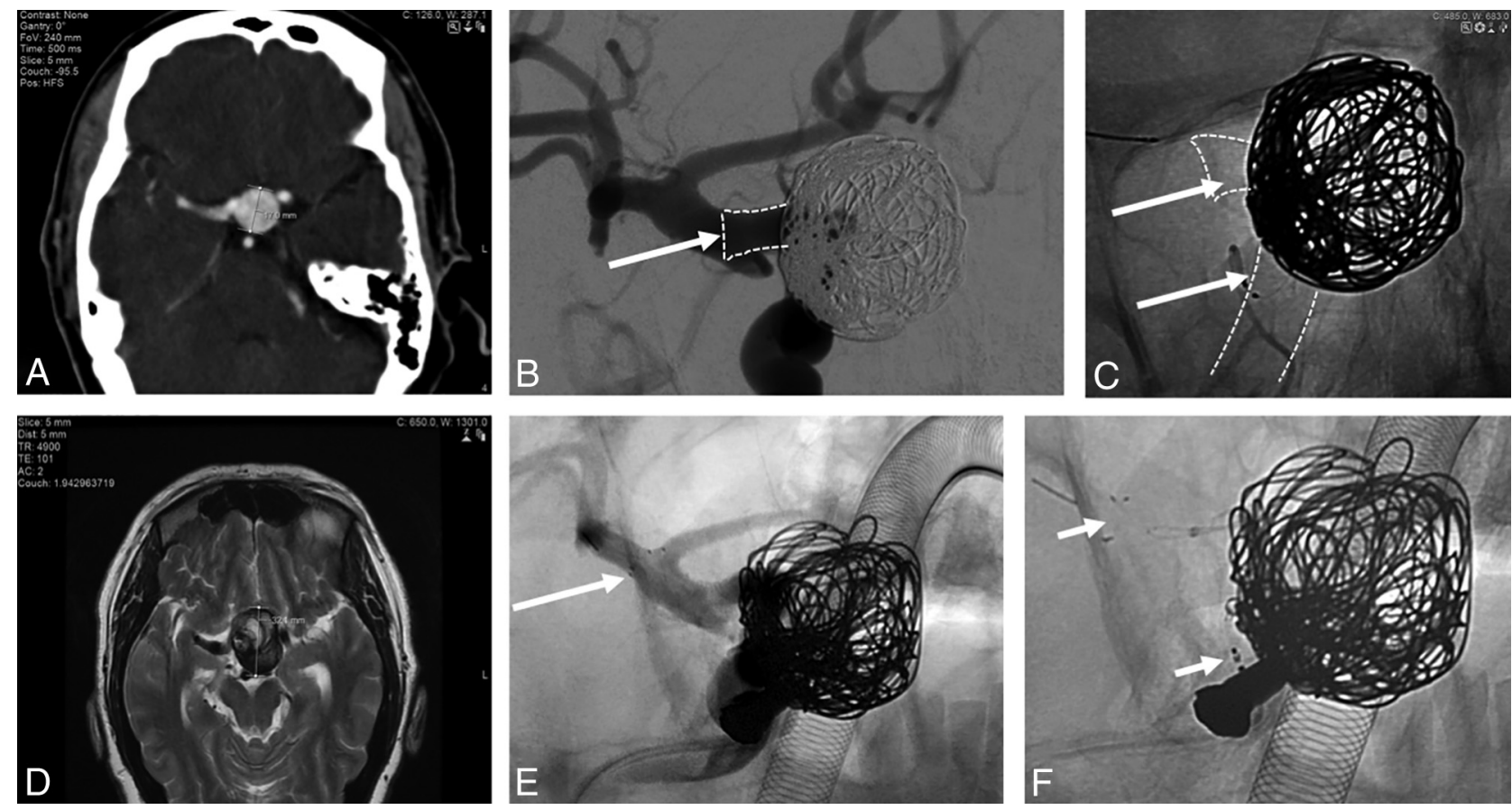

FIG 2. Pipeline Shield case. A, CTA shows a right ICA paraophthalmic segment aneurysm measuring $17 \mathrm{~mm}$ in maximal sac diameter before treatment. B, Digital subtraction angiography oblique view shows the aneurysm after treatment with a $5 \times 14 \mathrm{~mm}$ Pipeline Shield and 7 adjunctive coils. The landing zone (arrow) was selected as shown because the ICA paraophthalmic segment lumen was 5.00 mm in diameter, the ICA posterior communicating artery segment lumen was $4.75 \mathrm{~mm}$ in diameter (wider at the infundibulum), and the ICA terminal segment was $5.5 \mathrm{~mm}$ in diameter. The nominal maximum diameter of the largest Pipeline Shield is $5.0 \mathrm{~mm}$ with a maximum unconstrained diameter of $5.25 \mathrm{~mm}$. $C$, Different oblique view without subtraction after treatment. The Pipeline Shield (arrows) has a flared appearance as it bulges into the infundibulum of the ICA posterior communicating artery segment. D, MR imaging at 5 months postprocedure shows that the aneurysm cross-sectional diameter had increased during the 5-month interval from 17 to $32 \mathrm{~mm}$. The stent was no longer covering the entire aneurysm neck in the ICA paraophthalmic segment. $E$ and $F$, The aneurysm was re-treated by telescoping a larger-diameter flow-diverter device (FRED, MicroVention; arrows show proximal and distal markers), measuring $5.5 \times 14 \mathrm{~mm}$, through the Pipeline Shield, across the small segment of uncovered neck, and landing the stent in the ICA terminal segment. Anesthetic equipment is superimposed over the image.

\section{DISCUSSION}

This pragmatic and non-industry-sponsored outcome study adds to the limited safety and efficacy outcome evidence of the thirdgeneration Pipeline Shield. In contrast to earlier generation PEDs, which have been studied extensively, ${ }^{3,7,15-19}$ there is only 1 recent industry-sponsored prospective study (Pipeline Flex Embolization Device with Shield Technology (PFLEX) $)^{16,20}$ and several case reports ${ }^{21,22}$ examining the Pipeline Shield when used to treat aneurysms that have not acutely ruptured. We analyzed the 30-day and 1-year mortality and morbidity rates, and the 6and 18-month radiographic aneurysm occlusion outcomes.

\section{Clinical Outcomes}

Our overall mortality rate was $2.3 \%$, which was lower than the $3.8 \%$ seen in the IntrePED study (the largest clinical trial for previous generation PEDs) ${ }^{3}$ and higher than the PFLEX study, which was $0 \% .{ }^{20}$ The 1 death in our study was caused by a subdural hematoma 15 days after treatment.

The overall morbidity rate of $6.8 \%$ in our study ( 1 periprocedural and 2 postprocedural major adverse events in 44 procedures) is similar to that in a very similar study using previousgeneration devices $(10.0 \%)^{9}$ as well as the IntrePED study $(7.4 \%){ }^{3}$ Two of the major adverse events occurred in giant aneurysms, and 1, in a large aneurysm, again highlighting the higher complication risk associated with PED (or any) treatment of large or giant aneurysms ( $\geq 10 \mathrm{~mm}$ ). Because the PFLEX study used a different outcome classification from the IntrePED study classification, which was used in the current study, a direct comparison with the PFLEX outcomes was limited. For indirect comparison, the PFLEX study showed $0 \%$ major strokes (defined as the NIHSS score increasing by 4 points) or neurologic deaths at 1 year postprocedure. However, there were 6\% (3/50) procedure-related adverse events (headache, diplopia, and retroperitoneal hematoma) categorized as serious in the PFLEX study. Events including a carotid dissection and a cerebral infarction (the NIHSS score changed by $\leq 3$ points) also occurred but were considered nonserious events.

In vitro, ex vivo, and in vivo studies have shown reduced thrombogenicity of the Pipeline Shield compared with the PED without phosphorylcholine surface modification. ${ }^{8,23,24}$ There are no clinical data to prove that surface modification results in improved clinical outcomes, but the following observations suggest that surface modification does not worsen clinical outcomes. No thromboembolic events occurred during the procedure; 1 patient $(2.3 \%)$, who also had atrial fibrillation, had a periprocedural thromboembolic event; and no thromboembolic events occurred during postprocedural follow-up. In the PFLEX study, 
there were no procedural or periprocedural thromboembolic events; but 1 patient experienced a thromboembolic event at 1 year (2\%). In comparison, the previous-generation PEDs led to a periprocedural thromboembolic event rate of $6.5 \%$ and $3.3 \%$ in the ipeline Embolization Device for the intracranial treatment of aneurysms trial (PITA) ${ }^{1}$ and IntrePED ${ }^{3}$ studies respectively; and in 2 large meta-analyses of flow-diverter device treatment, the rate was $3.6 \%$ and $5 \% .{ }^{25,26}$ At a median follow-up of 19 months, there was a cumulative $4.7 \%$ thromboembolic event rate in the IntrePED study. Although the numbers are too small for a comparative multivariate analysis, a very similar pragmatic study at our center using previous-generation PEDs yielded a cumulative $10.0 \%$ thromboembolic event rate. ${ }^{9}$ Taken together, the data from these studies and the current study suggest that there is no reason to refute the in vitro, ex vivo, and in vivo (animal and clinical) evidence of the low thrombogenicity of the Pipeline Shield.

\section{Occlusion Rates}

Our complete occlusion (Raymond scale 1) rate was $69.2 \%$ at 6 months and $82.7 \%$ at 18 months. Our results are not dissimilar to those of flow-diverter device studies in general (ranging between $55 \%$ and $95 \%$ during various follow-up intervals $)^{27,28}$ or the studies described below using the PED only. Our study of the first 2 generations of PEDs, also using 3D-TOF-MRA follow-up, yielded similar complete occlusion rates at 6 and 18 months (65.6\% and $78.1 \%$, respectively). ${ }^{9}$ At the 1 -year follow up of the PFLEX study, ${ }^{20}$ the complete aneurysm occlusion rate was $81.8 \%$.

We note that the pipeline for uncoilable or failed aneurysms study (PUFS) ${ }^{5}$ study had a complete occlusion rate of $86.8 \%$ at 1 year follow up and the PITA ${ }^{1}$ had $93.3 \%$ at 6-month follow up, which were higher than our occlusion rates. Although statistical comparison cannot be made directly among the different studies, we make the following tentative observations: First, the mean aneurysmal sac size in these studies was larger than that in our study (18.0 and $11.5 \mathrm{~mm}$ compared with $9.0 \mathrm{~mm}$ in our study), so the putative occlusion rate differences are unlikely to be caused by a difference in aneurysm size (indeed, a meta-analysis with flow-diverter devices showed no relationship between the occlusion rates and sac diameter of aneurysms ${ }^{5}$ ). Second, the putative occlusion rate differences are unlikely to be caused by a difference in adjunctive coiling because the PITA study adjunctive coil rate was higher $(51.6 \%)$, while the PUFS rate was lower $(0.9 \%)$ compared with our rate $(28.8 \%)$. A lack of relationship between occlusion rates and adjunctive coil rates might be expected because there is little evidence that adjunctive coiling when using flow-diverter devices is beneficial. ${ }^{29}$ Anecdotally, there is more motivation for adjunctive coiling to prevent rupture of large aneurysms during thrombosis rather than to influence occlusion rates. Third, additional overlapping PEDs are anecdotally thought to influence occlusion rates by increasing mesh density. It is plausible that the putative occlusion rate differences are caused by a difference in mesh density because the mean number of Pipeline Shields used per aneurysm was 0.9 (or if nontarget aneurysms are ignored, 1.0), whereas in PITA and PUFS, the rates were 1.5 and 3 , respectively. We also note that the PFLEX study ${ }^{20}$ had an occlusion rate similar to that in our study using a similar Pipeline Shield rate of 1.1.

Aneurysm sac diameter is considered an important factor influencing the occlusion rate in endovascular treatment, especially in aneurysm coiling. However, as mentioned above, a metaanalysis with flow-diverter devices showed no relationship between the occlusion rates and sac diameter of aneurysms. ${ }^{5}$ Our results also did not show that the sac diameter of the Pipeline Shield influences occlusion rates.

In contrast to the first 2 generations of PEDs studied previously, ${ }^{9}$ no significant difference in neck width was seen when occluded and nonoccluded subgroups were compared following Pipeline Shield treatment.

\section{Strengths and Limitations}

Studies such as PFLEX, ${ }^{20}$ PITA, ${ }^{1}$ and PUFS ${ }^{5}$ used DSA as the follow-up technique for PED-treated aneurysms. There has been widespread adoption of flow-diverter devices with a range of follow-up methods and time points, and a recent meta-analysis that compared MRA and DSA concluded that both 3D-TOF-MRA and contrast-enhanced MRA can be used reliably to follow up flow-diverter devices. ${ }^{30}$ The sensitivity and specificity of TOF-MRA were $86 \%$ and $95 \%$, respectively. Contrast-enhanced MRA had a sensitivity and specificity of 90\% and $92 \%$. MRA has been chosen as a suitable follow-up imaging technique in pragmatic flow-diverter device studies including the flow diversion in the treatment of aneurysms (FIAT) randomized controlled trial, which analyzed the safety and efficacy of PEDs. ${ }^{31}$ As in a study of previous-generation PEDs, ${ }^{9}$ we used 3D-TOF-MRA.

Despite the data from the meta-analysis, there may be concerns that the PED can result in a marked local signal void due to a larger bimetallic surface area coverage and radiofrequency shielding, ${ }^{32,33}$ which may cause false-positive detection of in-stent stenosis. ${ }^{34,35}$ However, the impact of this potential overestimation of in-stent stenosis was negligible in our study because no instent stenosis was seen on the 3D-TOF-MRA follow-up.

A further concern using 3D-TOF-MRA as a follow-up technique may relate to false-positive detection of intra-aneurysmal residual flow, which has been recognized with TOF-MRA due to T1-weighted hyperintensity of the thrombus. ${ }^{36}$ False-positive detection of intra-aneurysmal residual flow in our study is likely to be very low because other sequences (T2-weighted) and scan planes (multiplanar reformat) were routinely reviewed. In our institution, we have yet to discover a false-positive after a subsequent DSA, nor was a false-positive seen in a previous PED study using 3D-TOF-MRA when analysis of multiple MR imaging planes and sequences was also performed at follow-up. ${ }^{9}$ Furthermore, cross-sectional MR imaging confirmed complete occlusion because a decrease in the size of the aneurysm sac on cross-sectional imaging appears to be the single most consistent sign of durable aneurysm occlusion (likely implying full endothelialization of the device construct and secondary exclusion of the aneurysm from the parent circulation). ${ }^{37,38}$ In contrast, intra-aneurysmal thrombosis in a nonoccluded growing aneurysm can occasionally appear on DSA as an apparently occluded aneurysm (false-negative). 
Although contrast-enhanced MRA may theoretically overcome some of these potential concerns, the data from the metaanalysis (particularly at $1.5 \mathrm{~T}$ ) do not support a change of practice at our institution from TOF to contrast-enhanced MRA, to obviate the potential drawbacks of TOF. ${ }^{36,39}$

Nonetheless, a limitation of this study is that DSA was not performed for follow-up, which would have allowed direct comparison of efficacy outcomes with many previous studies and provided complementary information.

Another limitation of this study is that it was performed in a single center and is retrospective; however, the results of this pragmatic study are likely to be generalizable to similar centers. ${ }^{9}$ This would be other centers with a similar operator number (3 performing PEDs), operator experience (10, 9, and 4 years of interventional neuroradiology experience at the point of first deployment of the Shield), neurovascular multidisciplinary team composition (2 neurosurgeons, 4 interventional neuroradiologists, 1 stroke neurologist), and a population at risk (3.5 million in a unit treating 160-200 aneurysms per year).

A further limitation of the study is the small absolute number of cases. However, small numbers can be expected in a singlecenter study (we note that the National Institute of Clinical Excellence in the UK estimates that 60 PEDs are used in the entire UK per year ${ }^{40}$ ), and even the seminal PITA study consisted of only 31 aneurysms. ${ }^{1}$ Furthermore, because PFLEX included 50 patients with 50 unruptured target aneurysms, the current study, which includes 41 patients with 44 unruptured target aneurysms, almost doubles the total number of Pipeline Shield cases studied (94 unruptured aneurysms).

The overall incidence of DWI positive foci presumably representing thromboembolic events following endovascular treatment of intracranial aneurysms is approximately $50 \%$, with no significant difference between coiling and flow diversion. ${ }^{13}$ According to some studies from the coiling and flow-diversion literature, there is no association between the presence of DWI lesions and neuropsychological examination performance. ${ }^{41,42}$ Nonetheless, future studies may wish to routinely perform postprocedural DWI to investigate the rate of these foci after Pipeline Shield deployment.

\section{CONCLUSIONS}

Our retrospective study Pipeline Embolization Device with Shield Technology in Unruptured Aneurysms (PEDSU) is a pragmatic and non-industry-sponsored study into clinical and radiographic (safety and efficacy) outcomes of the third-generation Pipeline Shield device. The study adds to the limited outcome evidence regarding the third-generation Pipeline Shield used to treat aneurysms that have not acutely ruptured. Our results demonstrated that occlusion rates and safety outcomes are similar compared with those in previously published studies using other flow-diverter devices or the first 2 generations of PEDs. Followup with 3D-TOF-MRA showed similar PED occlusion results compared with those acquired with MRA or DSA from other studies.

Disclosures: Naga Kandasamy-UNRELATED: Travel/Accommodations/Meeting Expenses Unrelated to Activities Listed: Medtronic, Comments: funding for conferences and academic meetings. Jonathan Hart-UNRELATED: Travel/ Accommo-dations/Meeting Expenses Unrelated to Activities Listed: MicroVention, Comments: Money was not paid directly to me, but costs of travel, accommodation, and course fees were covered by the company to attend the "Brainstorm" meeting in Edinburgh 2019.

\section{REFERENCES}

1. Nelson PK, Lylyk P, Szikora I, et al. The Pipeline Embolization Device for the intracranial treatment of aneurysms trial. AJNR Am J Neuroradiol 2011;32:34-40 CrossRef Medline

2. Premarket approval. https://www.accessdata.fda.gov/scripts/cdrh/ cfdocs/cfpma/pma.cfm?ID=P100018. Accessed June 12, 2019

3. Kallmes DF, Hanel $\mathrm{R}$, Lopes $\mathrm{D}$, et al. International retrospective study of the Pipeline embolization device: a multicenter aneurysm treatment study. AJNR Am J Neuroradiol 2015;36:108-115 CrossRef Medline

4. Kallmes DF, Brinjikji W, Boccardi E, et al. Aneurysm study of Pipeline in an observational registry (ASPIRe). Interv Neurol 2016;5:89-99 CrossRef Medline

5. Becske T, Kallmes DF, Saatci I, et al. Pipeline for uncoilable or failed aneurysms: results from a multicenter clinical trial. Radiology 2013;267:858-68 CrossRef Medline

6. Pereira VM, Kelly M, Vega P, et al. New Pipeline Flex device: initial experience and technical nuances. J Neurointerv Surg 2015;7:920-25 CrossRef Medline

7. Colby GP, Lin LM, Caplan JM, et al. Immediate procedural outcomes in 44 consecutive Pipeline Flex cases: the first North American single-center series. J Neurointerv Surg 2016;8:702-09 CrossRef Medline

8. Girdhar G, Li J, Kostousov L, et al. In-vitro thrombogenicity assessment of flow diversion and aneurysm bridging devices. J Thromb Thrombolysis 2015;40:437-43 CrossRef Medline

9. Yang SH, Hampton T, Kandasamy N, et al. Outcome study of the Pipeline embolization device for treatment of intracranial aneurysms at a single UK institution. Br J Neurosurg 2017;31:661-67 CrossRef Medline

10. Comin J, Kallmes DF. Platelet-function testing in patients undergoing neurovascular procedures: caught between a rock and a hard place. AJNR Am J Neuroradiol 2013;34:730-34 CrossRef Medline

11. Brinjikji W, Lanzino G, Cloft $\mathrm{HJ}$, et al. Platelet testing is associated with worse clinical outcomes for patients treated with the Pipeline Embolization Device. AJNR Am J Neuroradiol 2015;36:2090-95 CrossRef Medline

12. Siller-Matula JM, Trenk D, Schrör K, et al. Response variability to P2Y 12 receptor inhibitors. JACC Cardiovasc Interv 2013;6:1111-28 CrossRef Medline

13. Brasiliense LBC, Stanley MA, Grewal SS, et al. Silent ischemic events after Pipeline embolization device: a prospective evaluation with MR diffusion-weighted imaging. J Neurointerv Surg 2016;8:1136-39 CrossRef Medline

14. Shapiro M, Becske T, Riina HA, et al. Toward an endovascular internal carotid artery classification system. AJNR Am J Neuroradiol 2014;35:230-36 CrossRef Medline

15. Duckworth EAM, Nickele C, Hoit D, et al. The first North American use of the Pipeline flex flow diverter. J Neurointerv Surg 2016;8:e8 CrossRef Medline

16. Martínez-Galdámez M, Lamin SM, Lagios KG, et al. Periprocedural outcomes and early safety with the use of the Pipeline Flex Embolization Device with Shield Technology for unruptured intracranial aneurysms: preliminary results from a prospective clinical study. J Neurointerv Surg 2017;9:772-76 CrossRef Medline

17. Lylyk P, Miranda C, Ceratto R, et al. Curative endovascular reconstruction of cerebral aneurysms with the Pipeline embolization device: the Buenos Aires experience. Neurosurgery 2009;64:632-42 CrossRef Medline

18. Szikora I, Berentei Z, Kulcsar Z, et al. Treatment of intracranial aneurysms by functional reconstruction of the parent artery: the 
Budapest experience with the Pipeline embolization device. AJNR Am J Neuroradiol 2010;31:1139-47 CrossRef Medline

19. Fischer S, Vajda Z, Perez MA, et al. Pipeline Embolization Device (PED) for neurovascular reconstruction: initial experience in the treatment of 101 intracranial aneurysms and dissections. Neuroradiology 2012;54:369-82 CrossRef Medline

20. Martínez-Galdámez M, Lamin SM, Lagios KG, et al. Treatment of intracranial aneurysms using the Pipeline flex embolization device with shield technology: angiographic and safety outcomes at 1year follow-up. J Neurointerv Surg 2019;11:396-99 CrossRef Medline

21. Griessenauer CJ, Goren O, Dalal SS, et al. Pipeline Embolization Device with Shield Technology for intracranial aneurysms: an initial U.S. experience. World Neurosurg 2018;119:0-14 CrossRef Medline

22. Orlov K, Kislitsin D, Strelnikov N, et al. Experience using Pipeline Embolization Device with Shield Technology in a patient lacking a full postoperative dual antiplatelet therapy regimen. Interv Neuroradiol 2018;24:270-73 CrossRef Medline

23. Matsuda Y, Chung J, Lopes DK. Analysis of neointima development in flow diverters using optical coherence tomography imaging. $J$ Neurointerv Surg 2018;10:162-67 CrossRef Medline

24. Hagen MW, Girdhar G, Wainwright J, et al. Thrombogenicity of flow diverters in an ex vivo shunt model: effect of phosphorylcholine surface modification. J Neurointerv Surg 2017;9:1006-11 CrossRef Medline

25. Arrese I, Sarabia R, Pintado R, et al. Flow-diverter devices for intracranial aneurysms: systematic review and meta-analysis. Neurosurgery 2013;73:193-200 CrossRef Medline

26. Brinjikji W, Murad MH, Lanzino G, et al. Endovascular treatment of intracranial aneurysms with flow diverters: a meta-analysis. Stroke 2013;44:442-47 CrossRef Medline

27. Byrne JV, Beltechi R, Yarnold JA, et al. Early experience in the treatment of intra-cranial aneurysms by endovascular flow diversion: a multicentre prospective study. PLoS One 2010;5:e12492-98 CrossRef

28. Saatci I, Yavuz K, Ozer C, et al. Treatment of intracranial aneurysms using the Pipeline Flow-Diverter Embolization Device: a single-center experience with long-term follow-up results. AJNR Am J Neuroradiol 2012;33:1436-46 CrossRef Medline

29. Sweid A, Atallah E, Herial N, et al. Pipeline-assisted coiling versus Pipeline in flow diversion treatment of intracranial aneurysms. $J$ Clin Neurosci 2018;58:20-24 CrossRef Medline

30. Ahmed SU, Mocco J, Zhang X, et al. MRA versus DSA for the follow-up imaging of intracranial aneurysms treated using endovascular techniques: a meta-analysis. J Neurointerv Surg 2019;11:1009-14 CrossRef Medline
31. Raymond J, Gentric JC, Darsaut TE, et al. Flow diversion in the treatment of aneurysms: a randomized care trial and registry. $J$ Neurosurg 2017;127:454-62 CrossRef Medline

32. Wall A, Kugel H, Bachman R, et al. 3.0 T vs. 1.5 T MR angiography: in vitro comparison of intravascular stent artifacts. J Magn Reson Imaging 2005;22:772-79 CrossRef Medline

33. Wang Y, Truong TN, Yen C, et al. Quantitative evaluation of susceptibility and shielding effects of nitinol, platinum, cobalt-alloy, and stainless steel stents. Magn Reson Med 2003;49:972-76 CrossRef Medline

34. Blum MB, Puchner S, Funovics MA, et al. Quantification and detectability of in-stent stenosis with $C T$ angiography and MR angiography in arterial stents in vitro. AJR Am J Roentgenol 2007;189:123842 CrossRef

35. Lettau M, Sauer A, Heiland S, et al. Carotid artery stents: in vitro comparison of different stent designs and sizes using CT angiography and contrast-enhanced MR angiography at 1.5T and 3T. AJNR Am J Neuroradiol 2009;30:1993-97 CrossRef Medline

36. Boddu SR, Tong FC, Dehkharghani S, et al. Contrast-enhanced time-resolved MRA for follow-up of intracranial aneurysms treated with the Pipeline Embolization Device. AJNR Am J Neuroradiol 2014;35:2112-18 CrossRef Medline

37. Slater LA, Soufan C, Holt M, et al. Effect of flow diversion with Silk on aneurysm size: a single-center experience. Interv Neuroradiol 2015;21:12-18 CrossRef Medline

38. Shapiro M. Neurovascular topics in the endovascular arena. SAMvascular-audience response (AR) self-assessment module (SAM). In: Proceedings of the Annual Meeting of the American Society of Neuroradiology, Long Beach, California. April 22-27, 2017

39. Attali J, Benaissa A, Soize S, et al. Follow-up of intracranial aneurysms treated by flow diverter: comparison of three-dimensional time-of-flight MR angiography (3D-TOF-MRA) and contrastenhanced MR angiography (CE-MRA) sequences with digital subtraction angiography as the gold standard. J Neurointerv Surg 2016;8:81-86 CrossRef Medline

40. National Institute for Health and Care Excellence. Medical technologies guidance [MTG10], 2012. https://www.nice.org.uk/ guidance/mtg10/chapter/4-NHS-considerations. Accessed May 14,2017

41. Kang DH, Hwang YH, Kim YS, et al. Cognitive outcome and clinically silent thromboembolic events after coiling of asymptomatic unruptured intracranial aneurysms. Neurosurgery 2013;72:638-45 CrossRef Medline

42. Iosif C, Camilleri Y, Saleme S, et al. Diffusion-weighted imagingdetected ischemic lesions associated with flow-diverting stents in intracranial aneurysms: safety, potential mechanisms, clinical outcome, and concerns. J Neurosurg 2015;122:627-36 CrossRef Medline 